\title{
A systematic analysis of protein palmitoylation in Caenorhabditis elegans
}

\author{
Matthew J Edmonds and Alan Morgan*
}

\begin{abstract}
Background: Palmitoylation is a reversible post-translational protein modification which involves the addition of palmitate to cysteine residues. Palmitoylation is catalysed by the DHHC family of palmitoyl-acyl transferases (PATs) and reversibility is conferred by palmitoyl-protein thioesterases (PPTs). Mutations in genes encoding both classes of enzymes are associated with human diseases, notably neurological disorders, underlining their importance. Despite the pivotal role of yeast studies in discovering PATs, palmitoylation has not been studied in the key animal model Caenorhabditis elegans.

Results: Analysis of the C. elegans genome identified fifteen PATs, using the DHHC cysteine-rich domain, and two PPTs, by homology. The twelve uncategorised PATs were officially named using a dhhc-x system. Genomic data on these palmitoylation enzymes and those in yeast, Drosophila and humans was collated and analysed to predict properties and relationships in C. elegans. All available C. elegans strains containing a mutation in a palmitoylation enzyme were analysed and a complete library of RNA interference (RNAi) feeding plasmids against PAT or PPT genes was generated. To test for possible redundancy, double RNAi was performed against selected closely related PATs and both PPTs. Animals were screened for phenotypes including size, longevity and sensory and motor neuronal functions. Although some significant differences were observed with individual mutants or RNAi treatment, in general there was little impact on these phenotypes, suggesting that genetic buffering exists within the palmitoylation network in worms.
\end{abstract}

Conclusions: This study reports the first characterisation of palmitoylation in C. elegans using both in silico and in vivo approaches, and opens up this key model organism for further detailed study of palmitoylation in future.

Keywords: DHHC, Palmitoyl acyl-transferase, Palmitoyl-protein thioesterase, Neuronal ceroid lipofuscinosis

\section{Background}

Palmitoylation, specifically $S$-palmitoylation, is the posttranslational modification of proteins with the 16-carbon fatty acid palmitate. Unlike other lipid modifications of proteins, palmitoylation is reversible. The formation of its thioester link to cysteine residues is catalysed by palmitoyl acyl-transferases (PATs), also known as DHHCs after their conserved active site aspartic acid-histidinehistidine-cysteine motif, and the removal of palmitate is catalysed by palmitoyl-protein thioesterases (PPTs) [1-3]. Palmitoylation occurs on diverse substrates, both soluble and transmembrane, in a variety of cell types and tissues. As such, it is important in the regulation of many cellular processes, including Ras signalling and synaptic

\footnotetext{
* Correspondence: amorgan@liverpool.ac.uk

Department of Cellular and Molecular Physiology, Institute of Translational Medicine, University of Liverpool, Crown St., Liverpool L69 3BX, UK
}

plasticity, and altered palmitoylation is associated with various human diseases, notably neurological disorders [4-6].

Although palmitoylation as a post-translational modification in eukaryotic cells had been known about for many years [7], it was not until relatively recently that the enzymes involved were identified $[1,8-10]$. The realisation that the DHHCs shared their eponymous motif in a cysteine-rich domain (DHHC-CRD) allowed easy searching of whole genome data for putative DHHCs. This method has allowed the prediction of 23 such genes in humans [6,9], 24 in mice [4], 22 in Drosophila [11] and eight predicted, of which seven are confirmed, in yeast [10]. The DHHC motif is also the active site of these enzymes [12] and many of the predicted DHHCs have since been validated experimentally as having palmitoyltransferase enzymatic activity [13]. 
The PPTs present more of a challenge to study systematically due to the lack of a common identifying motif. The mammalian cytosolic PPT acyl-protein thioesterase 1 (APT1) was originally discovered through its action in removing $\left[{ }^{3} \mathrm{H}\right]$-palmitate from $\mathrm{G \alpha}$ subunits [14] and has homology to another PPT, APT2. PPT1 was discovered through its biochemical activity against palmitoylated $\mathrm{H}$ Ras [15] and has been shown to be localised to lysosomes [16] or synaptic vesicles and synaptosomes [17] instead of the cytoplasm. A second lysosomal enzyme, PPT2, was found through homology to PPT1 but has not been shown to have activity against palmitoyl-proteins $[3,18]$.

Numerous proteome-scale studies in recent years have enabled the identification of proteins which undergo palmitoylation in different cell types and organisms [19-24]. However, there is comparatively little known about which enzyme(s) palmitoylate or depalmitoylate which substrate (s). This is partly due to the workload in characterising individual enzymes or substrates to obtain this specific information. Identification of these enzyme-substrate pairs can be better directed by examining the effects of disruption of each enzyme to show which cellular pathways they may regulate. The nematode worm C. elegans is a useful experimental tool for probing functions of genes in well conserved processes using simple assays. As well as mutant strains, individual gene function may be disrupted by knocking down expression using RNA interference (RNAi). This can be performed simply by feeding animals with bacteria expressing double-stranded RNA (dsRNA) against the gene of interest $[25,26]$.

There has been some confusion in the literature about C. elegans DHHCs, with figures of 15 [4], 16 [1] and 17 [27] genes being quoted. However, there has been no definitive analysis of putative DHHC enzymes or any assessment of their palmitoylating activity. The only member of the DHHC family of enzymes which has been studied in C. elegans is SPE-10. The spe-10 gene was named after a spermatogenesis defect in fibrous body-membranous organelles, where the protein is localised $[27,28]$. There are some stress resistance phenotypes which have been observed in spe-10 mutants, including an increase in lifespan in some, though not all, experiments and increased resistance to UV exposure and high temperature $\left(35^{\circ} \mathrm{C}\right)$ but not paraquat, a reactive oxygen species generator [29].

The literature on PPTs in C. elegans is limited to ppt-1 [30], with no studies on its APT1 orthologue ath-1. PPT-1 was shown to have similar activity to the human orthologue [31] and knockouts have a number of mild phenotypes including delays in the developmental moult from the final larval stage, L4, into adults and onset of egglaying [30]. Electron microscopy showed defects in mitochondria in energetically active tissues, including neurons [30]. Given the suitability of C. elegans as a model system for probing questions about both development and neuronal function [32,33], coupled with the importance of palmitoylation in these systems $[4,30,34]$, a more thorough analysis could open up new avenues of research within the field.

In this study, the $C$. elegans DHHC enzymes were first defined. In silico sequence analysis was performed to show the differing relationships between the DHHCs and PPTs both in reference to other members of the families in $C$. elegans and those in other organisms. A screen conducted using both mutant strains and an RNAi knockdown approach was performed to assess effects on gross phenotypes relating to basic parameters and behaviours of $C$. elegans. These data will serve as a useful platform for other researchers wishing to study palmitoylation in vivo in this simple model organism.

\section{Results}

Identification and naming of the C. elegans DHHC enzyme family

Before exploring palmitoylation in C. elegans, it was first necessary to identify its DHHC enzymes and gain clues as to possible phenotypes from what is already known about them and their counterparts in other organisms. A search of the specialist database WormBase (version WS207) for the Pfam tag assigned to the DHHC motif uncovered 15 genes. Four of these 15 were previously named: $d h h c-1, d h h c-2$, tag-233 and spe-10. The remainder were annotated only with their gene code. These were renamed in line with official conventions using the dhhc- $x$ nomenclature previously started. tag-233, a temporarily assigned gene name, was also renamed. Where possible, the number assigned to the $d h h c-x$ nomenclature was based on homology to the H. sapiens DHHCs (Additional file 1). The spe-10 name is based upon a published spermatogenesis defect phenotype [27-29] and so was not altered to avoid confusion within the literature. The old and new gene names and their respective codes are shown in Table 1 and the collated information available on WormBase is in Additional file 2. These changes in gene nomenclature were effective from release WS235 of WormBase.

\section{Sequence analysis}

A sequence alignment of the primary sequence of the 15 C. elegans DHHCs confirms that all of them contain the DHHC motif required for enzymatic activity within a cysteine-rich domain (Figure 1A). The positions of these cysteines relative to the DHHC motif are absolutely conserved and correspond to those originally observed in this domain [8]. To assess whether the $C$. elegans DHHCs conform to the common structure found in this family, a domain structure diagram was constructed using domains predicted from the primary 
Table 1 C. elegans strain and RNAi clone availability

\begin{tabular}{|c|c|c|c|}
\hline Gene & Gene code & Available mutant(s) (allele) & RNAi clone source \\
\hline dhhc-1 & F09B12.2 & tm4272 (tm4272) & Vidal library \\
\hline dhhc-2 & Y47H9C.2 & RB1044 (ok990) & Vidal library \\
\hline$d h h c-3$ & F33D11.12 & & In-house \\
\hline$d h h c-4$ & ZK757.4 & & In-house \\
\hline dhhc-5 & R13F6.5 & & Vidal library \\
\hline$d h h c-6$ & M18.8 & & In-house \\
\hline dhhc-7 & C17D12.1 & & Vidal library \\
\hline$d h h c-8$ & Y39E4B.7 & & In-house \\
\hline dhhc-9 & $\mathrm{C} 43 \mathrm{H} 6.7$ & VC2067 (gk985) & Vidal library \\
\hline dhhc-10 & K02G10.1 & & Vidal library \\
\hline dhhc-11 & $\mathrm{T} 22 \mathrm{E} 7.2$ & & Vidal library \\
\hline dhhc-12 & F59C6.2 & VC2039 (gk1013), VC2244 (gk981) & Vidal library \\
\hline dhhc-13 & $\mathrm{H} 32 \mathrm{C} 10.3$ & VC108 $(g k 36)$ & In-house \\
\hline dhhc-14 & D2021.2 & VC771 (gk330), VC918 (ok1032) & In-house \\
\hline spe-10 & AC3.10 & BA744 (hc104) & In-house \\
\hline ath-1 & K04G2.5 & RB1484 (ok1735) & Vidal library \\
\hline ppt-1 & F44C 4.5 & MN1 (gk139), VC166 (gk131), VC168 (gk134), VC183 (gk139), VC184 (gk140) & Vidal library \\
\hline
\end{tabular}

sequence (Figure 1B). In general, DHHCs have been found to have four transmembrane domains (TMDs), though some have more, and the DHHC-CRD is normally located in a cytoplasmic loop between the second and third TMDs [1,4,6,35]. The majority of the C. elegans DHHCs fit this description, although there are some exceptions. DHHC-11 has no TMDs preceding the DHHC-CRD, while DHHC-13 and -14 have five and three TMDs respectively preceding the DHHC-CRD. DHHC-13 and -14 are the only $C$. elegans DHHCs which contain multiple ankyrin repeats in the $\mathrm{N}$-terminal section of the sequence, and these enzymes show closest homology to the mammalian DHHCs containing this domain (Additional file 1). Three enzymes, DHHC- 5 and -8 and SPE-10, also contain a palmitoyltransferase conserved C-terminal (PaCCT) motif. This motif is only present in a subset of DHHC enzymes across organisms, but has been shown to be required for the activity of the $S$. cerevisiae DHHCs Swf1 and Pfa3 [36].

The protein sequences were also subjected to a phylogenetic analysis. The enzymes mostly form pairs which are closely related on the resulting phylogenetic tree (Figure 2A) and some of the features correlate well with the domain structures (Figure 1B). For example the ankyrin repeat-containing proteins $\mathrm{DHHC}-13$ and -14 are one such pair. The exception is DHHC-11, which can probably be accounted for by its lack of two N-terminal TMDs compared with the rest of the family.
Given the lack of experimental information on the vast majority of the C. elegans DHHCs, they were compared with the DHHC family in other model organisms and humans. The sequences of the conserved DHHC-CRD region of DHHC enzymes from S. cerevisiae, D. melanogaster and $H$. sapiens were combined with the C. elegans sequences for a large scale analysis. Whilst the consensus sequence for DHHCs is quite precisely defined, it has been noted that there are variations within it which seem to be tolerated [1]. With this in mind, the DHHC sequences were aligned with the focus on the region containing the full consensus sequence (Figure 2B). There does indeed seem to be variation in how important individual residues in the consensus sequence are. The only residues which are absolutely conserved are the aspartate of the DHHC motif and the asparagine which is the penultimate residue in the sequence. Although absolutely conserved among the C. elegans DHHCs, many of the cysteine residues which form the CRD are missing from some enzymes from other species. Even the DHHC motif, required for enzymatic activity, is not absolutely conserved. The $S$. cerevisiae DHHCs Akr1, Akr2 and Pfa5 have a tyrosine instead of a histidine residue in the third position, although these enzymes retain their palmitoyltransferase activity [1]. The histidine residue in the second position is changed to an arginine in D. melanogaster CG17197 and glutamine in $H$. sapiens DHHC13 (also called Huntingtin- 


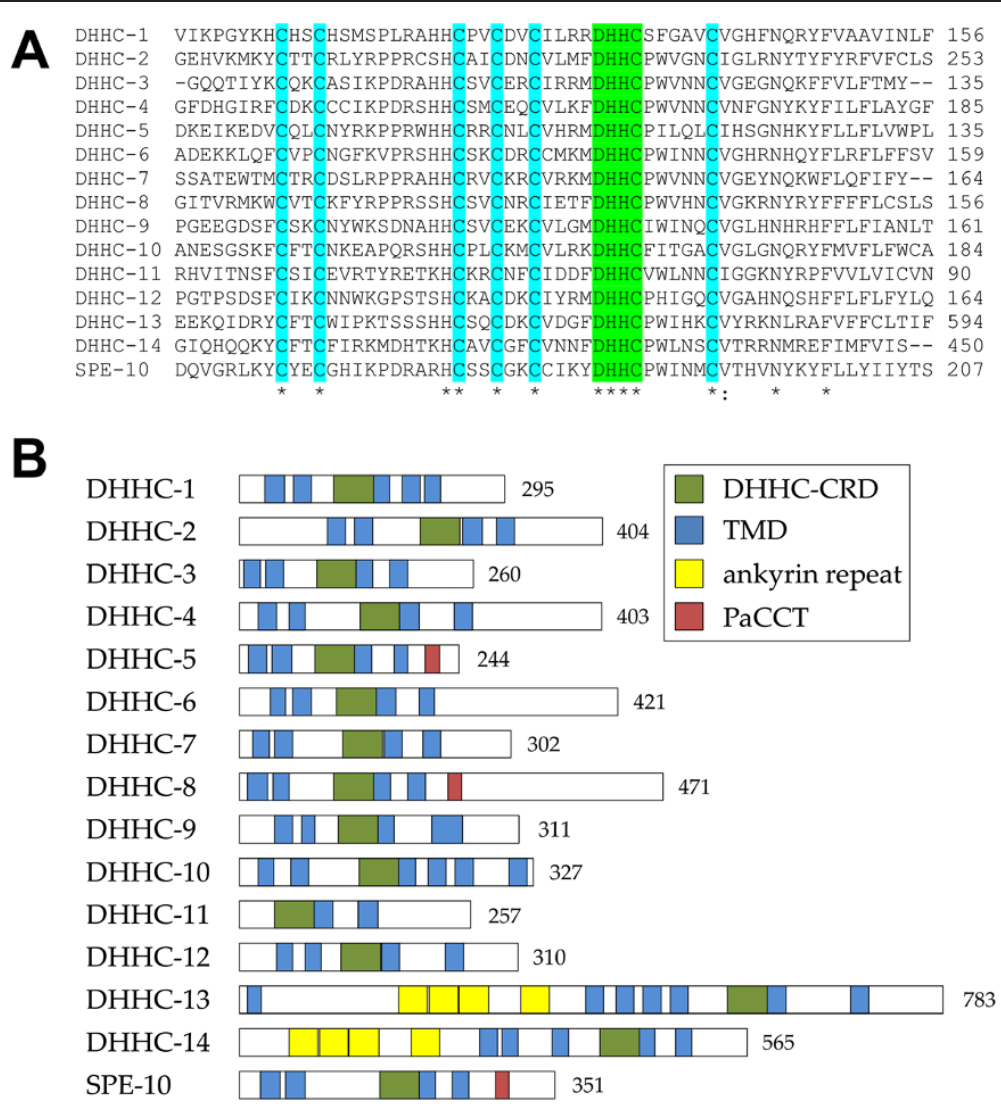

Figure 1 Sequence analysis of the putative C. elegans DHHC enzymes. (A) An alignment of the cysteine-rich domain (DHHC-CRD) of the putative C. elegans DHHC enzymes. The absolutely conserved DHHC motif is highlighted in green and conserved cysteine residues in cyan. The position of the final residue in the sequence shown is indicated on the right. (B) The predicted domain structure of the C. elegans DHHCs is represented in schematics drawn to scale. Features indicated are the DHHC-CRD (green), transmembrane domains (blue), ankyrin repeats (yellow) and palmitoyltransferase conserved C-terminal (PaCCT) (red). The sequence length in amino acids is indicated on the right.

interacting protein 14-like (HIP14L)). Again, while the former has not been studied, HIP14L is known to have palmitoyltransferase activity [37]. The cysteine in the DHHC motif is changed to a serine residue in the $D$. melanogaster DHHC $\beta 1,4-\mathrm{N}$-acetylgalactosaminyl-transferase B pilot (GABPI). Given that this cysteine residue is required to form the palmitoyl-enzyme intermediate [12] and its mutation to serine is a common way to inactivate DHHCs, it is likely that GABPI has no palmitoyltransferase activity in vivo. In a phylogenetic tree using the DHHC-CRD of DHHCs from these same organisms (Figure $2 \mathrm{C}$ ), the C. elegans DHHCs retain the pairs seen on the phylogenetic tree of their full-length sequences, and their altered positions in relation to each other are likely to reflect differing areas of similarity around the DHHC-CRD compared with the $\mathrm{N}$ - and Ctermini. The C. elegans DHHCs also appear mostly to be related, albeit distantly in some cases, to proteins in other organisms, allowing predictions to be made based on knowledge from other organisms.
In addition to the DHHC-CRD, there are two other regions of relatively high sequence conservation which have been observed in DHHCs. There is an aspartate-prolineglycine (DPG) motif commonly next to TMD2 and a threonine-threonine- $\mathrm{x}$-glutamate (TTxE) motif commonly next to TMD4 [1]. The DPG motif can be found in C. elegans DHHC-2, $-3,-5$ and -7 , and the TTxE motif in $C$. elegans DHHC-3, $-4,-6$ and -10 and SPE-10. The functional significance of these motifs is not yet known.

\section{The $C$. elegans palmitoyl-protein thioesterases}

Unlike the DHHCs, there are no unifying motifs in the PPTs which allow easy genomic searches. This limits the process of finding PPTs in unexplored genomes to searching for orthologues of known PPTs. The two known sub-families of PPTs, the PPTs and the APTs, are well represented across diverse organisms, although not many have both types of PPT. There is generally a reasonable degree of sequence conservation within orthologues of each individual protein, as can be seen in sequence 

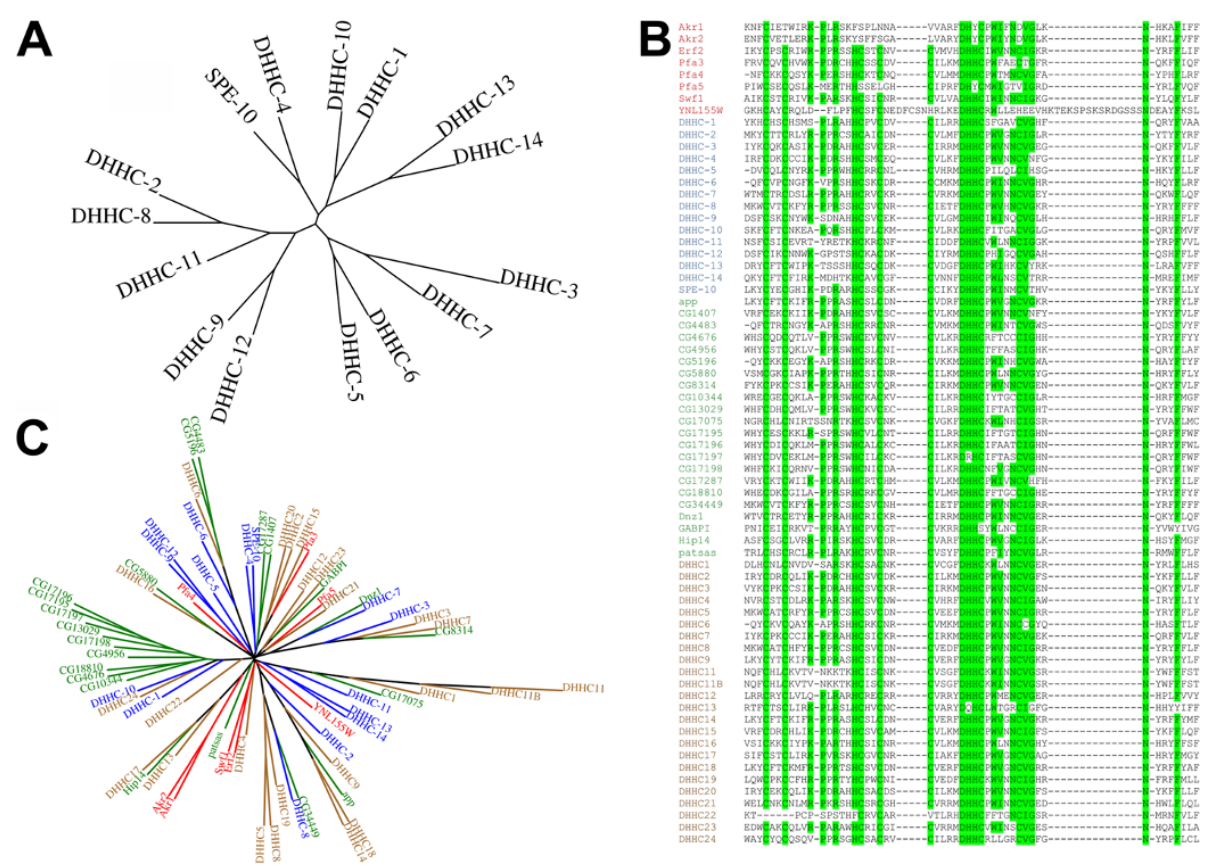

Figure 2 Phylogenetic analysis of DHHC enzymes from yeast, worms, fruit flies and humans. (A) The 15 DHHCs from C. elegans were subjected to phylogenetic analysis and the resulting trees were rendered using Interactive Tree of Life [71]. (B) An alignment of the DHHC-motif cysteine-rich domain (DHHC-CRD) of the known DHHC enzymes from S. cerevisiae (red lettering), C. elegans (blue), D. melanogaster (green) and H. sapiens (brown) is shown. Specific residues in the consensus sequence $C x_{2} C x_{3}(R / K) P x R x_{2} H C x_{2} C x_{2} C x_{4} D H H C x W(V / I) \times N C(I / N) G x_{2} N x_{3} F$ [1] are highlighted in light green. (C) The conserved DHHC-CRD from these organisms (C) was also subjected to phylogenetic analysis. Species and colours are as in panel (B).

alignments (Additional file 3). However, there is no one conserved region in common between the two sequences. In C. elegans there are two PPTs, PPT-1 and ATH-1, which are orthologues of $H$. sapiens PPT1 and APT1 respectively.

The sequences of the PPTs in S. cerevisiae, C. elegans, $D$. melanogaster and $H$. sapiens were subjected to phylogenetic analysis and a phylogenetic tree was constructed, showing a clear divide between the PPT and APT subfamilies (Additional file 4). The APT sub-family seems to be derived from the $S$. cerevisiae thioesterase enzyme Apt1, whereas the PPT subfamily is only present in the more complex organisms. Apt1 was shown by a systematic GFP-tagging study [38] to be localised to the cytoplasm and nucleus in yeast. This is consistent with the known localisation of $H$. sapiens APT1 in the cytoplasm [14], compared with PPT1 and -2 , which are lysosomal $[3,16]$. It is therefore likely that the $C$. elegans enzymes will follow a similar pattern, with PPT-1 lysosomal and ATH-1 cytoplasmic.

\section{Derivation of mutant strains and feeding RNAi clones}

By collating the C. elegans DHHC and PPT enzymes and examining their sequences properties in silico, several potential relationships between these enzymes and with those in other organisms were revealed. Having assessed their predicted properties, the next step was to assess whether disruption of their expression by mutation or RNAi knockdown causes readily observable phenotypes.

WormBase and the National Bioresource Project for the Experimental Animal "Nematode C. elegans" website (http://www.shigen.nig.ac.jp/c.elegans/index.jsp) were used to find existing strains containing a unique mutation only in that gene (Table 1, Additional file 5). An alternative to using mutant strains is to knockdown expression of proteins simply through feeding RNAi. For this purpose, we used the Vidal C. elegans open reading frame (ORF) RNAi Library of bacterial RNAi feeding strains [39], which contains ten of the 15 DHHCs and both PPTs. The genes not present in the Vidal library were cloned into the empty vector to give a complete set of RNAi clones for the DHHC and PPT families (Table 1). Despite the effectiveness of RNAi in many tissues, $C$. elegans neurons in particular can be refractory to its effects [40]. A strain deficient for $r r f-3$ (pk1426 allele, designated NL2099), which suppresses amplification of secondary siRNAs, shows a general increase in sensitivity to RNAi, including in neurons [41] and so was used as the feeding RNAi background strain in this study.

\section{Morphology}

All strains appeared to have normal morphology, behaviour and fertility during standard culture conditions. To quantify their morphology they were analysed using WormTracker software, which automatically locates an 
animal on a video feed of a plate, assigns a skeleton of points along the body and uses this to give precise morphological measurements [42,43]. Wild-type N2 animals had an average length of $1222 \mu \mathrm{m}$ and width of $78 \mu \mathrm{m}$ (Additional file 6). Of the mutant strains tested, only ppt-1 (gk134) had a significant difference in length from $\mathrm{N} 2$, reduced to $915 \mu \mathrm{m}$, but this was not observed in the other ppt-1 alleles. Mutants for $d h h c-1$ and -12 (gk1013) showed a small but significant reduction in width to around $70 \mu \mathrm{m}$, and $d h h c-9,-13$, and spe-10 showed an increase to $85-90 \mu \mathrm{m}$.

When $r r f-3$ RNAi-hypersensitive mutants were fed negative control bacteria, which had no insert in the pGL4440 expression vector (L4440), the animals were on average $1445 \mu \mathrm{m}$ long and $86 \mu \mathrm{m}$ wide (Additional file 7). There is no reported figure for the length of $r r f-3$ mutants in the literature, although no obvious morphological differences were reported when this strain was first published [41] and on the plates they appear identical to N2 animals by eye. When $r r f-3$ animals were treated with RNAi against a selection of genes, no significant differences in length or width were observed.

\section{Behavioural assays}

Locomotion is a measure of overall neuronal and muscular function and can be assessed in solution [44] or on solid media [45]. All mutant strains were subjected to thrashing assays in solution (Figure 3A, B). One of the dhhc-12 mutant strains ( $g$ k1013) showed a significant decrease in locomotion, and dhhc-14 (ok1032) and ppt-1 ( $k$ k131) showed a significant increase. However, in each case the strain(s) containing the other allele available for the gene showed a non-significant difference in the opposite direction. The most likely explanation for this discrepancy is the presence of secondary mutations as a result of the mutagenesis process; it seems unlikely that similar alleles should produce such disparate effects. Thrashing assays were also carried out on RNAi-treated rrf-3 mutants covering all the DHHC (Figure $3 \mathrm{C}$ ) and PPT (Figure 3D) genes. The only gene which gave a significant difference was $d h h c-6$, whose knockdown gave a reduction in thrashing rate. Locomotion of all the mutant strains was also assessed on solid medium (Additional file 8, panels A and B). Only the dhhc-9 (gk985) and ppt-1 ( $g k 134)$ strains showed a significant difference from wild-

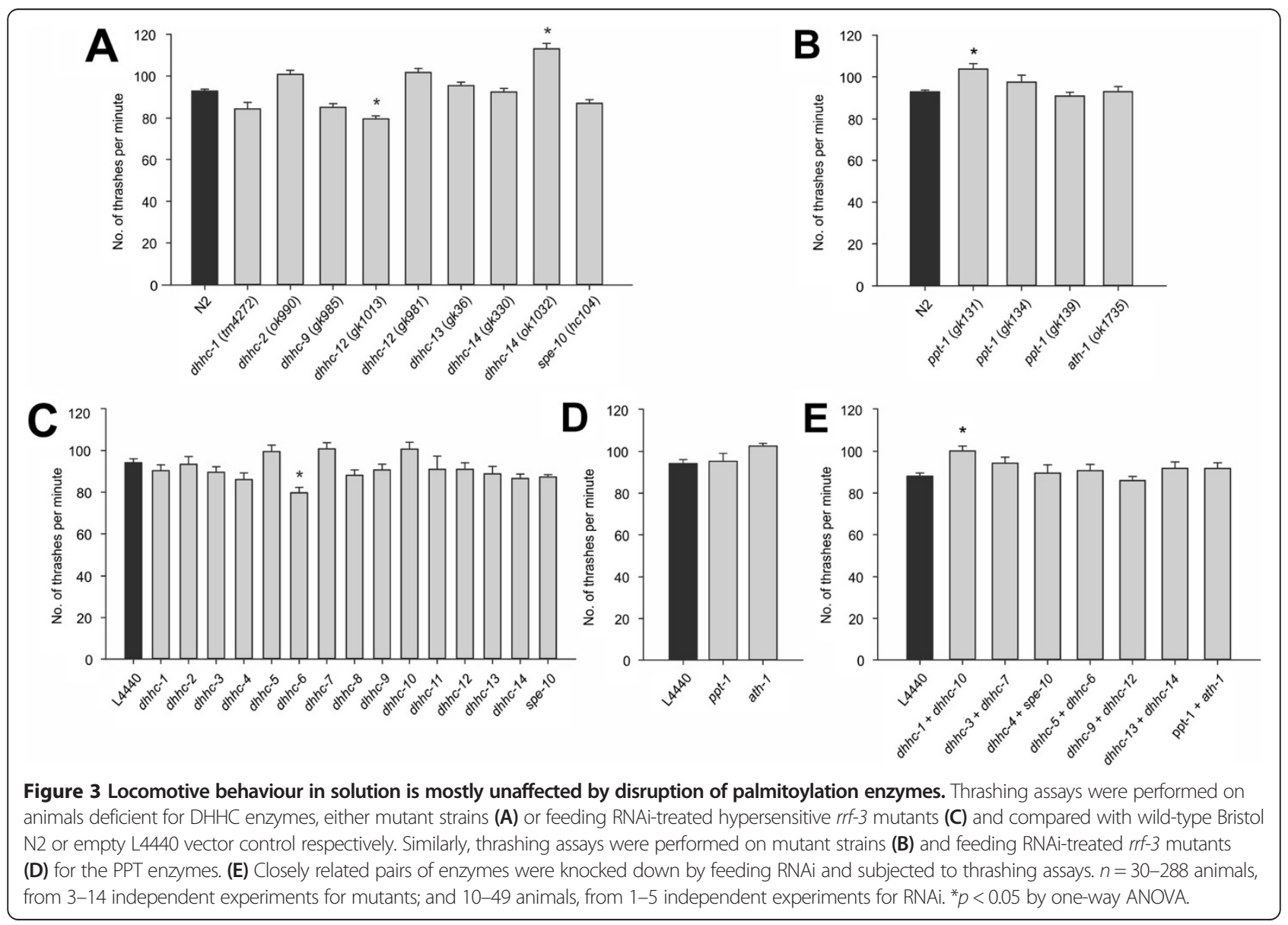


type locomotion. When an RNAi approach was used, none of the genes tested showed an obvious change in locomotory rate (Additional file 8, panel C).

As palmitoylation is known to be involved in a number of neurodegenerative processes [46-51], a possible readout would be a faster than normal decrease in locomotion rate as C. elegans ages. All of the mutant strains except $d h h c-1$, which was not yet available at the time of the experiment, were synchronised and subjected to thrashing assays as they aged (Additional file 9). None of the strains showed a significant difference from the shape of decay in the wild-type $\mathrm{N} 2$ rate of thrashing.

It is possible that this lack of strong locomotory phenotypes is due to a certain level of redundancy, that is, that other DHHCs can take over the roles of missing enzymes. Feeding RNAi can be used to knock down expression of multiple genes at the same time, albeit at a reduced efficiency compared with feeding RNAi against only one gene, by culturing the animals on a mixture of bacterial strains (Additional file 10) [25,52,53]. In order to test whether redundancy may play a part in locomotion assays, pairs of closely related DHHCs were knocked down based on phylogenetic analysis (Figure 3E). These thrashing assays only showed a difference with knockdown of $d h h c-1$ and -10 together, giving a small but significant increase in speed. The rest of the combinations thrashed at the same rate as the negative control.

It has been observed that knockdown of two or more genes by mixing the feeding RNAi bacterial strains gives variable efficacy in an apparently gene-dependent manner $[25,52,53]$. Recently described is an approach in which the sequences from two or more genes of interest are cloned into the same vector, giving efficient knockdown of all the genes involved [52,53]. As there are only two known PPTs in C. elegans, this approach was tested by comparing the thrashing rates after knockdown of ppt-1 and ath-1 either by mixing the individual bacterial strains or by feeding a bacterial strain expressing the conjugated sequences from the individual vectors (Additional file 11). However, as no difference was seen from the negative control in either condition despite apparently more efficient knockdown (Additional file 10), this was not pursued further.

Another phenotype which can occur due to dysfunction of a subset of neurons is a defect in mechanosensation, whereby animals fail to respond to a mechanical stimulus by increasing movement in the opposite direction [33]. Selected mutant strains were tested for the presence of such a phenotype (Additional file 12). All of the strains were found to have normal responses to both anterior and posterior mechanical stimuli.

\section{Ageing phenotypes}

The only DHHC enzyme whose loss has been studied previously is SPE-10. One of the observations which has been made is a small increase in lifespan [29]. It was therefore decided to investigate whether any of the other mutant strains obtained also had any differences in lifespan. Values for mean and median lifespan, 90\% mortality and maximum lifespan of mutant strains are collated in Table 2. Survival plots of strains showing a significant difference from wild-type $\mathrm{N} 2$ animals are shown in Figure 4A, and those with no difference from N2 in Additional file 13, panel A. $d h h c-1, d h h c-9$ and both $d h h c-$ 14 mutants showed a decrease in mean lifespan. dhhc-14 ( $g k 330)$ mutants also showed a reduced median lifespan, and $d h h c-1$ and both $d h h c-14$ mutants had reduced time

Table 2 Survival analysis of DHHC and PPT mutant strains

\begin{tabular}{|c|c|c|c|c|c|}
\hline Strain & $n$ & Mean (days) & Median (days) & $90 \%$ mortality (days) & Maximum (days) \\
\hline $\mathrm{N} 2$ & 184 & 20 & 19 & 26 & 28 \\
\hline dhhc-1 (tm4272) & 97 & $17^{*}$ & 18 & $24^{+}$ & 27 \\
\hline dhhc-2 (ok990) & 100 & 20 & 19 & 26 & 34 \\
\hline dhhc-9 (gk985) & 143 & $19^{*}$ & 19 & 24 & 30 \\
\hline dhhc-12 (gk1013) & 50 & 19 & 20 & 26 & 26 \\
\hline dhhc-12 (gk981) & 93 & 21 & $21^{\dagger}$ & 26 & 28 \\
\hline dhhc-13 (gk36) & 93 & 21 & $20^{+}$ & 26 & 28 \\
\hline dhhc-14 (gk330) & 49 & $18^{*}$ & $18^{\dagger}$ & $20^{+}$ & 24 \\
\hline dhhc-14 (ok1032) & 48 & $18^{*}$ & 19 & $24^{+}$ & 24 \\
\hline spe-10 (hc104) & 95 & 21 & 19 & 29 & 35 \\
\hline ppt-1 (gk131) & 88 & 21 & 20 & $28^{+}$ & 33 \\
\hline ppt-1 (gk134) & 43 & 19 & 19 & 23 & 28 \\
\hline ppt-1 (gk139) & 86 & 19 & 19 & 27 & 30 \\
\hline ath-1 (ok1735) & 80 & 19 & 19 & $24^{+}$ & 33 \\
\hline
\end{tabular}

Various measures of survival were extracted from lifespan experiments comparing wild-type Bristol N2 and DHHC or PPT mutant strains. Statistical tests were applied to values varying from the control using OASIS [73]. ${ }^{*} p<0.01$ by the log-rank (Mantel-Cox) test. ${ }^{\dagger} p<0.01$ by Fisher's exact test. 

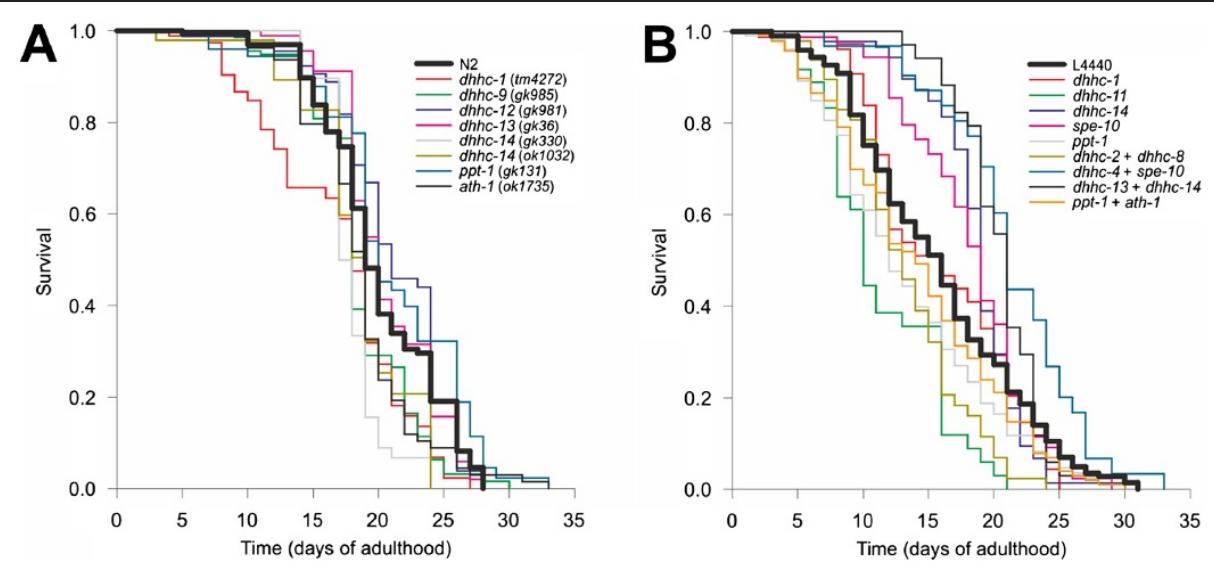

Figure 4 Disruption of some palmitoylation enzymes causes changes in survival. Survival plots are shown of mutant strains (A) and RNAi experiments (B) which differ significantly from the control in at least one measure (see Tables 2 and 3). The control strain was Bristol N2 for mutants and rrf-3 mutants fed bacteria containing the empty vector (L4440) for RNAi.

to $90 \%$ mortality. The spe-10 mutant did not show an increased mean or median lifespan as previously reported, although its maximum lifespan was extended considerably compared with wild-type. The ath-1 mutant also showed decreased time to $90 \%$ mortality; an increase in median lifespan was seen in $d h h c-12$, dhhc-13 and ppt-1 (gk131) mutants but not in other ppt-1 strains.

Lifespan analysis was also carried out on $r r f-3$ mutants treated with RNAi against genes of interest along with combinatorial RNAi with related enzymes identified by the phylogenetic analysis (Table 3). Survival plots are shown in Figure 4B, for those showing significant changes from the negative control strain, and Additional file 13, panel B, for those which did not. Of the RNAi experiments with single genes, dhhc-11 showed a decrease in mean lifespan. dhhc-14 and spe-10 had increased median lifespan, while that of ppt-1 was decreased. $d h h c-1$ and -14 also showed a decrease in time to $90 \%$ mortality which was also seen with their mutant strains, suggesting they may be involved in processes at older age. However, the reduced mean lifespan seen in the mutant strains was not observed with RNAi of $d h h c-1$ and -14 . Combined knockdown of $d h h c-2$ with -8 and ppt-1 with ath-1 gave a reduction in mean survival time. In contrast concurrent knockdown of $d h h c-4$ and spe-10 resulted in an increase in mean and median lifespan. The mixture of $d h h c-13$ and -14 also gave an increased median lifespan.

\section{Discussion}

In comparison with other organisms important to research, palmitoylation has been neglected as a field of study in the model organism C. elegans. Indeed, there is even confusion about the number of DHHC enzymes encoded in its genome, with figures of 15-17 reported [1,4,27]. Here, we have mined the official C. elegans genome database, Wormbase, using the conserved DHHC-CRD to conclusively show there are 15 DHHC genes encoded. A systematic naming procedure of $d h h c-x$ was applied to the unnamed C. elegans genes and their products in this family, except for spe-10 which has been previously published [27-29]. Sequence analysis confirmed that all of these proteins contained the requisite DHHC-CRD which is the active site [12,54]. Although palmitoyltransferase activity is yet to be directly observed with these enzymes, their overall structure is in line with enzymes whose activity has been confirmed. DHHC enzymes have a common structure of at least four TMDs, with the DHHC motif found in the cytoplasmic loop between TMD2 and TMD3 [1,4,6,35]. An obvious discrepancy in the C. elegans family occurs with DHHC-11, which omits the two TMDs normally found before the DHHC$\mathrm{CRD}$ and is isolated in the phylogenetic analysis. It is possible that its TMDs are missing as a result of a mutation producing a protein truncated at the N-terminus. Alternatively, palmitoylation of one of the cysteine residues upstream of the first TMD could mediate membrane attachment of the $\mathrm{N}$-terminus of the protein, compensating for the lack of TMDs in this region.

A phylogenetic analysis to group enzymes based on their relatedness can give an initial overview of information on the DHHCs within individual organisms and also with a wider perspective by including families from many organisms. A comparison of the $S$. cerevisiae DHHCs with the $H$. sapiens DHHCs showed several broad sub-families [1]. Some sub-families can be explained by the presence of common domains that are not in the majority of the enzymes. For example, the $S$. cerevisiae enzymes Akr1 and Akr2 cluster with the $H$. sapiens enzymes DHHC17/HIP14 and DHHC13/ HIP14L. All of these proteins have ankyrin repeat domains $\mathrm{N}$-terminal of their first TMD. A similar analysis was done including the $D$. melanogaster genes with the ankyrin repeat containing proteins clustered within the 
Table 3 Survival analysis of rrf-3 mutants treated with RNAi against DHHCs and PPTs

\begin{tabular}{|c|c|c|c|c|c|}
\hline RNAi strain & $n$ & Mean (days) & Median (days) & $90 \%$ mortality (days) & Maximum (days) \\
\hline$\llcorner 4440$ & 208 & 16 & 16 & 25 & 31 \\
\hline dhhc-1 & 79 & 16 & 16 & $24^{+}$ & 25 \\
\hline dhhc-11 & 47 & $12^{*}$ & 10 & 18 & 21 \\
\hline dhhc-14 & 99 & 19 & $19^{\dagger}$ & $22^{+}$ & 31 \\
\hline spe-10 & 79 & 18 & $19^{\dagger}$ & 24 & 29 \\
\hline ppt-1 & 108 & 13 & $12^{\dagger}$ & 23 & 30 \\
\hline ath-1 & 47 & 16 & 16 & 25 & 26 \\
\hline RNAi strain(s) & $n$ & Mean (days) & Median (days) & $90 \%$ mortality (days) & Maximum (days) \\
\hline$\llcorner 4440$ & 208 & 16 & 17 & 25 & 31 \\
\hline$d h h c-1+d h h c-10$ & 50 & 18 & 18 & 24 & 29 \\
\hline$d h h c-2+d h h c-8$ & 50 & $13^{*}$ & 13 & $20^{+}$ & 24 \\
\hline$d h h c-3+d h h c-7$ & 23 & 19 & 20 & 26 & 28 \\
\hline dhhc- $4+$ spe-10 & 34 & $21^{*}$ & $21^{\dagger}$ & 27 & 33 \\
\hline$d h h c-5+d h h c-6$ & 27 & 17 & 16 & 25 & 26 \\
\hline$d h h c-9+d h h c-12$ & 44 & 18 & 18 & 24 & 26 \\
\hline dhhc-13+dhhc-14 & 38 & 21 & $21^{+}$ & 24 & 30 \\
\hline$p p t-1+a t h-1$ & 143 & $14^{*}$ & 14 & 23 & 30 \\
\hline
\end{tabular}

Various measures of survival were extracted from lifespan experiments comparing hypersensitive rrf-3 animals treated with feeding RNAi empty vector L4440 control or against DHHC or PPT mutant strains (top). Mixtures of feeding RNAi bacteria were also used to assess simultaneous knockdown of related enzymes (bottom). Statistical tests were applied to values varying from the control using OASIS [73]. ${ }^{*} p<0.01$ by the log-rank (Mantel-Cox) test. ${ }^{\dagger} p<0.01$ by Fisher's exact test.r.

same group as above [11]. Application of phylogenetic analysis showed that the C. elegans DHHCs tend to form closely related pairs, but that these do not necessarily have high homology with other organisms. In addition, analysis of the two C. elegans PPTs showed one fell into each of the two known PPT subfamilies.

To examine the in vivo roles of palmitoylation enzymes a combination of mutant strains and feeding RNAi treatment were used to screen for strong phenotypes associated with their loss, both individually and in combinations. To gain an overview of all the analyses performed, a matrix was produced showing which genes were tested for each assay and the results (Figure 5). A handful of mutants showed slight changes in morphology but this was not seen in any RNAi experiments and is difficult to explain based on current knowledge. It is possible the mutant strains have a mild effect during development which results in morphological differences, or perhaps they retain more or fewer eggs. It is also unclear as to why some phenotypes were seen in mutants but not in RNAi experiments. One possibility is that the remaining low level of protein expression with RNAi is still enough for the enzyme to perform its function (Additional file 10). In addition, although we used the RNAi hypersensitive strain, $r r f-3$ [55], it may be that some cell types, such as neurons, are still relatively resistant to RNAi, leading to false negative results for enzymes expressed in those cell types. Alternatively, secondary mutations in the mutant strains could explain phenotypes observed in mutants but not with RNAi. Finally, differences in the molecular composition of the OP50 and HT115 strains used for mutant and RNAi experiments, respectively, could conceivably impact on lipid metabolism and hence palmitoylation within the worm. Although further repeat RNAi experiments could potentially reveal some additional statistically significant effects, these would still represent minor phenotypes. Therefore, although the above caveats need to be emphasized, it seems that mutation/ knockdown of individual palmitoylation genes does not result in strong phenotypes in C. elegans.

The DHHC SPE-10 has already been studied in relation to its spermatogenesis phenotype $[27,28]$ and resistance to certain stresses [29]. The spe-10 mutant strain exhibited reduced fertility, but the moderate increase in lifespan previously reported in some experiments [29] was not observed here (Table 2). However these experiments were performed at $20^{\circ} \mathrm{C}$ in contrast to the published observations at $25.5^{\circ} \mathrm{C}$. As spe- 10 mutants also have a resistance to heat stress [29], it is possible this is the main factor determining lifespan at higher temperatures. Nevertheless an increase in maximum lifespan was observed both in that study and here.

As many of the DHHC enzymes are closely related some other phenotypes may be masked by a compensatory effect where the similar enzyme takes over the function of the disrupted one. As well as this, many substrates can be palmitoylated by more than one palmitoyltransferase $[9,56,57]$. 


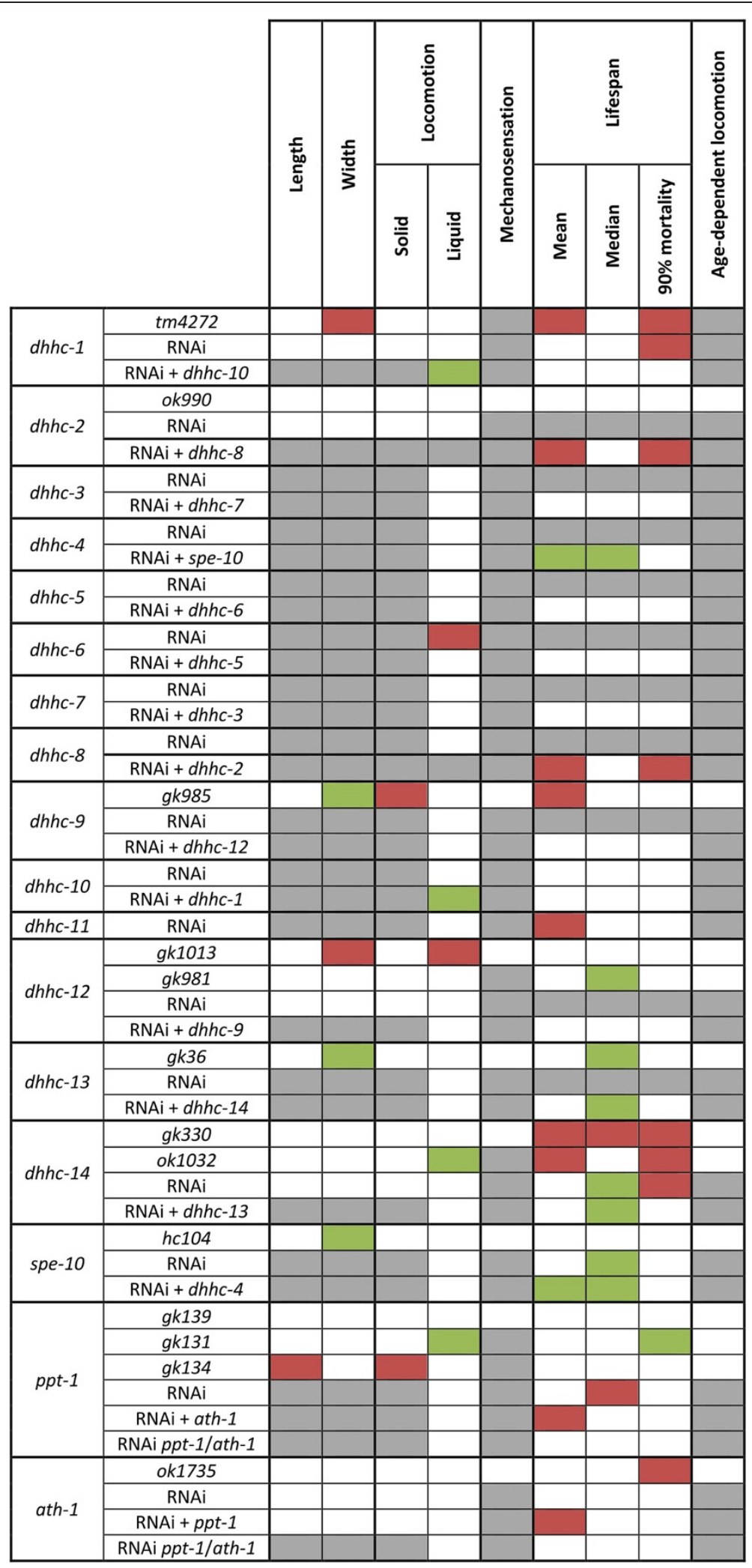

Figure 5 Summary of observations from the assays performed in this study. This matrix summarises the results presented in this study. A significant increase in quantity or time is coloured green and a significant decrease is in red. Grey indicates a test was not performed. 
In view of this, some combinatorial RNAi was also performed. Interestingly, some of the pairs of DHHCs which emerged from the phylogenetic analysis also share high homology with the same protein in other organisms. For example DHHC-4 and SPE-10 share homology to S. cerevisiae Pfa3, D. melanogaster CG1407 and H. sapiens DHHC2. This similarity in these pairs suggests that they may share common substrates and functions within the cell. Indeed this is the case with RNAi against both spe-10 and dhhc-4 simultaneously, extending the increase in mean and median lifespan seen with knockdown of spe-10 only (Table 3 ). Additionally the $d h h c-2$ mutant showed no change in lifespan, but when knocked down in combination with $d h h c-8$ there was a decrease in mean lifespan and time to $90 \%$ mortality. However other combinations did not result in additional phenotypes. It may be that efficient knockdown of many DHHC enzymes simultaneously is required to uncover more severe phenotypes.

The primary aim of the functional part of our systematic study was to identify strong phenotypes caused by mutation/knockdown of palmitoylation genes. Given that mutations in single PATs result in readily observable overt phenotypes in mammals and in flies [50,51,58,59], the lack of strong phenotypes in worms was somewhat unexpected. This may be due, in part, to the technical issues discussed above. Alternatively, it may be that PATs perform more basic cellular housekeeping functions in relatively simple organisms, which might be more readily compensated for, but take on more specialized roles in more complex animals. This notion is supported by the relative difficulty of finding strong phenotypes in $S$. cerevisiae, with knockout of multiple DHHC family members simultaneously often being required [20]. Another possibility is that the functional impact of key palmitoylated protein substrates may differ in divergent organisms. For example, mutation of a Drosophila PAT, HIP14, causes a strong impairment of neurotransmission that is entirely due to non-palmitoylation of cysteine string protein (CSP), as expression of a chimaeric CSP artificially targeted to synapses fully rescues this defect [59]. However, the extremely severe phenotype of CSP mutants seen in Drosophila [60] is not observed in $C$. elegans null mutants [61], so even if mutation of a worm PAT(s) completely prevented CSP palmitoylation, this would not result in strong effects on the phenotypes analysed in the present study.

The lack of any conserved motifs has limited the known PPTs to two sub-families: PPTs and APTs. Despite this, crystal structures of $H$. sapiens PPT1, PPT2 and APT1 show the same basic structure of an $\alpha / \beta$ hydrolase fold and a catalytic triad of serine, aspartate and histidine residues $[18,62,63]$. It is surprising that some organisms only have one of these enzymes given the relative abundance of different DHHCs. Analogous reversible post-translational modifications do not have quite this extreme a ratio of enzymes. The human genome contains around 500 kinases [64] compared with approximately 200 phosphatases [65] and in the ubiquitin system there are about 600 E3 ligases [66] and nearly 90 deubiquitinases [67]. It is possible that there are other PPTs which are yet to be discovered, otherwise mutants lacking them would be expected to have more severe phenotypes than are observed. Deletion of the only S. cerevisiae enzyme, Apt1, does not lead to any gross phenotype despite its depalmitoylation activity on G $\alpha$ [68]. Inhibition of APT1 by palmostatin B in Madin-Darby canine kidney epithelial (MDCK) cells prevented N-Ras depalmitoylation and altered its subcellular localisation from the plasma membrane and Golgi to all cellular membranes [69]. Despite this mislocalisation of an important signaling molecule, the cells showed no obvious phenotype. Similarly, a study identifying APT1 as the PPT for BK channels reported no phenotypes despite the channels becoming trapped in the ER [70]. If Apt1 is the only PPT in S. cerevisiae and it is responsible for depalmitoylation of substrates such as $\mathrm{G} \alpha$ and Ras then it seems there is some compensatory mechanism which prevents manifestation of a severe phenotype. Redundancy for these palmitoylated client proteins is a likely explanation for how the cell can buffer such effects on key substrates.

Mutations in the human PPT1 gene are known to cause the neurodegenerative disease infantile neuronal ceroid lipofuscinosis (INCL) [31]. ppt-1 mutants in $C$. elegans show only a mild mitochondrial defect which is considerably less severe than the human INCL symptoms [30]. Analysis of ppt-1 in this study produced somewhat challenging data from which to draw conclusions. The gk131 mutant showed an increase in thrashing rate, which was not replicated by RNAi, and the gk134 allele showed a decrease in locomotion on solid media. Lifespan effects also varied, with the $g k 131$ strain showing increased mean lifespan and time to $90 \%$ mortality, whereas ppt-1 RNAi showed a decreased median lifespan. Mutants of ath-1 showed a significant decrease in time to $90 \%$ mortality, and in combination with ppt-1 there was a reduction in mean lifespan. The disruption of both PPTs in the same C. elegans strain and the comparison of palmitoyl-proteomes of wild-type and PPT mutants may help shed light on the roles the PPTs play. This would be valuable in expanding the knowledge of PPT substrates and help to answer the question of whether PPTs have distinct sets of substrates or whether there is an overlap.

\section{Conclusions}

This study set out to define the DHHC family of enzymes in C. elegans, to characterise both the DHHCs and PPTs and to screen for strong phenotypes associated with disruption of them. As only spe-10 and ppt-1 had 
been previously characterised, the additional phenotypes identified for both these and other genes validate C. elegans as a model for studying palmitoylation in a simple in vivo context. C. elegans has been neglected as a tool for studying palmitoylation, but these data can be used as a starting point for future studies into specific enzymes, helping to further define the relationship between palmitoylation enzymes and diverse cellular processes.

\section{Methods}

\section{Database mining}

Initial searches for putative C. elegans DHHC enzymes were conducted on WormBase (http://www.wormbase. org/) using the Pfam tag of DHHC zinc-finger domain (PF01529). PPTs were found by basic local alignment search tool (BLAST) searching (http://blast.ncbi.nlm.nih. gov/) using the known $H$. sapiens PPT sequences; no characteristic PPT domain is known.

Basic information known about the H. sapiens, D. melanogaster and S. cerevisiae DHHCs and PPTs were found by searching the NCBI databases (http://www.ncbi.nlm.nih. gov/). In addition, the following organism-specific resources were used: Saccharomyces Genome Database (http://www. yeastgenome.org/); FlyBase (http://flybase.org/); WormBase.

\section{Sequence analysis}

BLAST searches to identify potential orthologues were conducted using the amino acid sequence of the relevant protein. Sequence alignments were performed using the Clustal Omega online program (http://www. ebi.ac.uk/Tools/msa/clustalo/). Colour highlighting of salient features was manually applied.

The domain structure diagram was constructed principally from information predicted by the InterProScan program (http://www.ebi.ac.uk/interpro/) and the TMpred program (http://www.ch.embnet.org/ software/TMPRED_form.html). Information on the $\mathrm{PaCCT}$ motif was obtained from a published analysis [36].

\section{Phylogenetic analysis}

To generate phylogenetic trees, alignments were first generated using BioEdit (Isis Pharmaceuticals; v6.0.5) and saved in .phy format for use in the suite of programs Phylip v3.69 (http://evolution.genetics.washington.edu/ phylip/getme.html). The .phy file was used as the "infile" for Seqboot. 2000 bootstraps were generated and used as the "infile" for Proml, using no outgroups and set to unrooted tree. 10 jumbles were used if computing power sufficed, otherwise one jumble was used. The "outtree" output file was used as the "intree" file for the Consense program. This final "outtree" file was uploaded to the Interactive Tree of Life server (http://itol.embl.de/index. shtml) [71] and formatted for display.

\section{Nematode husbandry}

All C. elegans strains were obtained from the Caenorhabditis Genetics Center (CGC; University of Minnesota, Twin Cities, MN, USA) except tm4272, which was obtained from the National Bioresource Project for the Experimental Animal "Nematode C. elegans" based in the lab of Dr Shohei Mitani (Tokyo Women's Medical University, Tokyo, Japan). All strains were verified by PCR analysis.

C. elegans were cultured in $60 \mathrm{~mm}$ plates on nematode growth medium agar (NGM; $\%(\mathrm{w} / \mathrm{v})$ agar, $0.3 \%(\mathrm{w} / \mathrm{v})$ $\mathrm{NaCl}, 0.25 \%(\mathrm{w} / \mathrm{v})$ peptone, $1 \mathrm{mM} \mathrm{CaCl}_{2}, 5 \mu \mathrm{g} \mathrm{ml}^{-1}$ cholesterol, $25 \mathrm{mM} \mathrm{KH}_{2} \mathrm{PO}_{4}, 1 \mathrm{mM} \mathrm{MgSO}{ }_{4}$ ) at $20^{\circ} \mathrm{C}$, seeded with $30 \mu \mathrm{l}$. coli OP50 culture (CGC) as a food source, using standard methods [32].

\section{RNAi}

RNAi feeding experiments were conducted using bacteria from the Vidal C. elegans ORF RNAi Library [39] (Source Bioscience, Nottingham, UK) where available, or were cloned in-house. All RNAi feeding bacteria were E. coli strain HT115, which lacks the dsRNA-specific RNase III but contains an isopropyl $\beta$-D-1-thiogalactopyranoside (IPTG)-inducible T7 RNA polymerase [72], carrying the pG-L4440 vector containing the relevant insert. The negative control vector contained no insert (L4440). hsp-1 was used as a positive control, as it gives a sterile phenotype [55].

RNAi plates of NGM containing $25 \mu \mathrm{g} \mathrm{ml}^{-1}$ carbenicillin and $1 \mathrm{mM}$ IPTG were poured 4-7 days before seeding with $50 \mu \mathrm{l}$ of the relevant bacterial strain and kept in the dark. After overnight induction, ten L3-L4 stage rrf3 (NL2099) worms were transferred to each plate. Once the next generation of worms had reached young adult stage, three adults were moved onto individual replica plates, allowed to lay eggs and removed the following day. These progeny were used for assays once they had reached adulthood.

RNAi knockdown efficiency was assessed by quantitative PCR (QPCR). Total RNA was extracted from worm pellets using Absolutely RNA Microprep Kit (Agilent, Stockport, UK). $8 \mu \mathrm{l}$ RNA was mixed with $1 \mu \mathrm{l} 40 \mu \mathrm{M}$ random hexamers and $1 \mu \mathrm{l} 10 \mathrm{mM}$ dNTPs and incubated at $70^{\circ} \mathrm{C}$ for $5 \mathrm{mi}-$ nutes then placed on ice. $4 \mu \mathrm{l} 5 \times \mathrm{RT}$ buffer, $1 \mu \mathrm{l}$ RNase OUT, $1 \mu \mathrm{l}$ BioScript (Bioline) and $4 \mu \mathrm{l} \mathrm{H}_{2} \mathrm{O}$ were added to each reaction and incubated at $25^{\circ} \mathrm{C}$ for 10 minutes, $42^{\circ} \mathrm{C}$ for 30 minutes and $85^{\circ} \mathrm{C}$ for 5 minutes before chilling on ice and storing at $-20^{\circ} \mathrm{C}$. QPCR was performed in a CFX Connect Real Time PCR Detection System (Bio-Rad). $7.5 \mu \mathrm{l} 2 \times$ SYBR mastermix was mixed with $1.5 \mu \mathrm{l} 2.5 \mu \mathrm{M}$ each primer (Additional file 14), $1 \mu \mathrm{l}$ cDNA template and $3.5 \mu \mathrm{H}_{2} \mathrm{O}$ and amplified using the following conditions: $95^{\circ} \mathrm{C}$ (10 minutes); 40 cycles of $95^{\circ} \mathrm{C}(15 \mathrm{~s}), 60^{\circ} \mathrm{C}(15 \mathrm{~s})$ and $72^{\circ} \mathrm{C}(15 \mathrm{~s})$ with a reading taken at the end of each cycle; $95^{\circ} \mathrm{C}$ (15 s); a gradient from $65^{\circ} \mathrm{C}$ to $95^{\circ} \mathrm{C}$ with $0.5^{\circ} \mathrm{C}$ 
increments. The $\Delta \Delta C_{\mathrm{T}}$ method was used to analyse expression normalised to act-1 expression and the expression level of each gene in negative control $r r f-3$ mutants fed L4440 bacteria (Additional file 10).

\section{Cloning}

In order to clone the RNAi vectors not present in the library, cDNA was first synthesised. $2 \mu \mathrm{g}$ total RNA from wild-type worms extracted using an Absolutely RNA Microprep Kit (Agilent) was made up to $16.45 \mu \mathrm{l}$ with diethylpyrocarbonate-treated (DEPC) $-\mathrm{H}_{2} \mathrm{O} .0 .8 \mu \mathrm{l} 50 \mu \mathrm{M}$ oligo(dT) primer was added and incubated at $70^{\circ} \mathrm{C}$ for ten minutes, then on ice for two minutes. $5 \mu$ Bioscript reaction buffer, $1.25 \mu \mathrm{l} 10 \mathrm{mM}$ dNTPs, $0.5 \mu \mathrm{l}$ RNase OUT and $1 \mu \mathrm{l}$ BioScript (Bioline) were added and reverse transcription performed under the following conditions: $25^{\circ} \mathrm{C}(10 \mathrm{mi}-$ nutes), $42^{\circ} \mathrm{C}$ (60 minutes), $90^{\circ} \mathrm{C}$ (2 minutes). $75 \mu$ l DEPC$\mathrm{H}_{2} \mathrm{O}$ was added to the products and stored at $-20^{\circ} \mathrm{C}$.

Reverse transcriptase PCR was performed using the primers listed in Additional file 15. $5 \mu \mathrm{l}$ cDNA, $2 \mu \mathrm{l}$ $10 \mu \mathrm{M}$ forward primer, $2 \mu \mathrm{l} 10 \mu \mathrm{M}$ reverse primer, $1 \mu \mathrm{l}$ $10 \mathrm{mM}$ dNTPs, $10 \mu \mathrm{l} 5 \times$ high fidelity or GC-richoptimised buffer and $0.5 \mu \mathrm{l}$ Phusion DNA polymerase were made up to a total reaction volume of $50 \mu \mathrm{l}$ with DEPC- $\mathrm{H}_{2} \mathrm{O}$. The PCR conditions were as follows: $98^{\circ} \mathrm{C}$ (2 minutes); $30-35$ cycles of $98^{\circ} \mathrm{C}(15 \mathrm{~s}), 60$ or $62^{\circ} \mathrm{C}$ (30 s), $72^{\circ} \mathrm{C}(15-30 \mathrm{~s}) ; 72^{\circ} \mathrm{C}$ (5 minutes); $4^{\circ} \mathrm{C}$ store.

Gateway $^{\text {Tм }}$ cloning was used to shuttle each PCR product into the pG-L4440 vector, with BP clonase $^{\mathrm{Tm}}$ II and LR clonase $^{\text {TM }}$ II (Sigma, Dorset, UK) steps performed as per the manufacturer's instructions. Successful incorporation into the pG-L4440 vector was verified by transforming into DH5 $\alpha$ cells and sequencing the purified DNA (DNA Sequencing \& Services, University of Dundee, UK). The vectors were then transformed into HT115 cells for consistency with the Vidal RNAi library.

For the RNAi vector containing sequences for both ppt-1 and ath-1, vectors containing ppt-1 and ath-1 individually were purified from overnight bacterial cultures. $20 \mu \mathrm{l}$ DNA was digested at $37^{\circ} \mathrm{C}$ in a reaction volume of $25 \mu \mathrm{l}$ : pG-L4440-ppt-1 was linearised using Acc65I; pG-L4440-ath-1 was digested with BsrGI to obtain the ath-1 sequence but retaining complementary 5 , overhangs to enable its ligation into the pG-L4440-ppt-1 vector. 5'-phosphates were removed from linearised pGL4440-ppt- 1 by incubating with $2 \mu \mathrm{l}$ shrimp alkaline phosphatase (Promega, Madison, WI, USA) for $15 \mathrm{mi}$ nutes at $37^{\circ} \mathrm{C}$. The products were subjected to agarose gel electrophoresis and the pG-L4440-ppt-1 and ath-1 bands were excised and purified into $50 \mu \mathrm{l}$ using a GenElute $^{\mathrm{TM}}$ Gel Extraction Kit (Sigma, Dorset, UK). The ligation reaction was performed with $1 \mu \mathrm{l}$ pG-L4440ppt- 1 added to $3 \mu \mathrm{l}$ ath-1, $2 \mu \mathrm{l} 5 \times \mathrm{T} 4$ ligase buffer, $1 \mu \mathrm{l} \mathrm{T} 4$ DNA ligase and $3 \mu \mathrm{l} \mathrm{H}_{2} \mathrm{O}$ and incubated at room temperature for one hour. The DNA was transformed into $\mathrm{DH} 5 \alpha$ cells and verified by test digest before transforming into HT115 cells.

\section{Morphology}

Individual worms were placed on a freshly seeded plate and allowed to acclimatise for ten minutes. WormTracker software (http://www.mrc-lmb.cam.ac.uk/wormtracker/; v2.0.3.1) $[42,43]$ was used to track the worms on a microscope stage controlled by computer through an Optiscan II box (Prior) and collect data via a DinoEye Eyepiece Camera (ANMO Electronics Corporation) over a two minute period. Data were analysed frame-by-frame in Worm Analysis Toolbox software (v1.9) and Microsoft ${ }^{\oplus}$ Office Excel $^{\odot}$ 2007. Any obvious outlier frames resulting from misanalysis by the software were removed and the mean values from all frames in the video of each worm were used.

\section{Lifespan}

To synchronise a worm strain, a relatively full plate of gravid adults was washed with $3.5 \mathrm{ml}$ sterile $\mathrm{H}_{2} \mathrm{O}$ and collected in a $15 \mathrm{ml}$ Falcon tube. $1.5 \mathrm{ml}$ bleach mixture (two parts commercial bleach to one part $5 \mathrm{M} \mathrm{NaOH}$ ) was added and the tube vortexed well every two minutes for a total of 10 minutes. The tubes were centrifuged at $1500 \mathrm{rpm}$ for one minute and the supernatant removed. $5 \mathrm{ml}$ sterile $\mathrm{H}_{2} \mathrm{O}$ was added and the tubes vortexed before centrifuging again. The supernatant was removed and the pellet of eggs was transferred to the edge of a seeded plate. These worms were picked onto lifespan plates once they reached adulthood, defined as day 0 .

For lifespan analysis of mutants, NGM agar plates were prepared containing $50 \mu \mathrm{M}$ fluorodeoxyuridine (FUdR), to prevent development of any eggs laid, and seeded with $50 \mu \mathrm{l}$ OP50. For RNAi lifespan studies, worms were already synchronised as a result of the replica plating procedure. Once they reached adulthood, these worms were transferred to lifespan plates seeded with $50 \mu \mathrm{l}$ RNAi bacteria but containing no FUdR. All worms were only fed their relevant RNAi bacterial strain throughout the assay, and transferred to fresh plates as necessary.

\section{Locomotion}

Worms were synchronised by allowing a gravid adult to lay eggs on a plate overnight before removing it. Worms were assayed once the progeny reached young adult age. For solid media individual worms were transferred to an unseeded or freshly seeded plate and allowed to acclimatise for five minutes. The number of body bends (complete movement of the head from one side to the other and back again) was observed over a period of two minutes [45]. To assess locomotory ability in solution, 
the worms were subjected to thrashing assays [44]. $100 \mu \mathrm{l}$ drops of Dent's Ringer solution (DRS; $10 \mathrm{mM}$ D-glucose, $10 \mathrm{mM}$ HEPES, $140 \mathrm{mM} \mathrm{NaCl}, 6 \mathrm{mM} \mathrm{KCl}, 3 \mathrm{mM} \mathrm{CaCl}_{2}$, $1 \mathrm{mM} \mathrm{MgCl}_{2}, \mathrm{pH}$ 7.4) containing $0.1 \%(\mathrm{w} / \mathrm{v}$ ) bovine serum albumin (BSA) were put in each well of a 96-well plate. One worm was picked into each well and allowed to equilibrate for at least 5 minutes. The number of thrashes (complete movement of the head from one side to the other and back again) in one minute was recorded.

For age-dependent locomotion, mutants were synchronised and maintained as for lifespan experiments. Every couple of days, ten worms of each strain were subjected to thrashing assays in $30 \mu \mathrm{l}$ drops of DRS + $0.1 \%$ BSA on a dish, then returned to their plate. This was continued until a strain had essentially no movement.

\section{Mechanosensation}

The root end of an eyebrow hair was glued to the end of a toothpick, leaving the tapered end free. Before each assay, this was sterilised by dipping in $70 \%$ ethanol and allowed to air dry. The worm to be assayed was transferred to an unseeded plate and allowed 5 minutes to acclimatise. Anterior touch response was tested by gently stroking the eyebrow hair across the body behind the pharynx, and posterior touch response by stroking just forward of the anus. A positive response was defined as stopping movement in the direction of the touch or reversal of direction of movement, or for posterior touch suddenly quicker forward movement [33].

\section{Statistical analysis}

All statistical analyses (with the exception of lifespan and age-dependent locomotion) and all graphs were produced using SigmaPlot (Systat Softare, Inc.; v.12.2.0.45). If two data sets were being directly compared, Student's $t$-test was used. For comparison of multiple data sets in one analysis, a one-way analysis of variance (ANOVA) was used. Age-dependent thrashing was compared using one-way analysis of covariance (ANCOVA) in Microsoft Office $^{\oplus}$ Excel $^{\bullet} 2007$.

Lifespan analyses were performed using the Online Application for the Survival Analysis of Lifespan Assays (OASIS; http://sbi.postech.ac.kr/oasis/introduction/) [73]. Mean lifespans were compared using the log-rank (MantelCox) test, and mortality at more specific time points was compared using Fisher's exact test.

\section{Availability of supporting data}

All supporting data are included as additional files.

\section{Additional files}

Additional file 1: A table showing orthologues of C. elegans $\mathrm{DHHC}$ enzymes in S. cerevisiae, D. melanogaster and H. sapiens.

Additional file 2: A table showing collated information available on C. elegans DHHC enzymes.

Additional file 3: An alignment of homologues of the palmitoylprotein thioestases PPT1 and APT1 in diverse species.

Additional file 4: A phylogenetic tree of PPT enzymes in S. cerevisiae, C. elegans, D. melanogaster and H. sapiens.

Additional file 5: A table showing information about the $\mathrm{C}$. elegans strains used in this study.

Additional file 6: A figure showing measurements of the morphology of DHHC and PPT mutants.

Additional file 7: A figure showing measurements of the morphology of rrf-3 mutants treated with feeding RNAi against DHHCs and PPTs.

Additional file 8: A figure showing locomotion on solid medium of DHHC and PPT mutants and feeding RNAi-treated rrf-3 mutants.

Additional file 9: A figure showing age-dependent declines in locomotion of DHHC and PPT mutant strains.

Additional file 10: A figure comparing RNAi knockdown efficiency between single, two mixed and two combined bacterial strains using quantitative PCR.

Additional file 11: A figure comparing locomotion after different methods of concurrent ppt-1 and ath-1 knockdown by feeding RNAi.

Additional file 12: A table showing mechanosensation data from DHHC and PPT mutant strains.

Additional file 13: A figure showing survival plots of $\mathrm{DHHC}$ and PPT mutants and RNAi-treated rrf-3 mutants which do not differ significantly from controls.

Additional file 14: A table listing the primers used for QPCR. Additional file 15: A table listing the primers used during RNAi vector cloning.

\section{Abbreviations}

ANCOVA: Analysis of covariance; ANOVA: Analysis of variance;

APT: Acyl-protein thioesterase; BLAST: Basic local alignment search tool; CGC: Caenorhabditis Genetics Center; DHHC-CRD: DHHC motif-containing cysteine-rich domain; dsRNA: Double-stranded RNA; GABPI:

B-1,4-N-acetylgalactosaminyl-transferase B; HIP: Huntingtin-interacting protein; INCL: Infantile neuronal ceroid lipofuscinosis; OASIS: Online application for survival analysis; PaCCT: Palmitoyltransferase conserved C-terminus; PAT: Palmitoyl acyl-transferase; PPT: Palmitoyl-protein thioesterase; QPCR: Quantitative polymerase chain reaction; RNAi: RNA interference; spe: Spermatogenesis-deficient; tag: Temporarily-assigned gene; TMD: Transmembrane domain.

\section{Competing interests}

The authors declare that they have no competing interests.

Authors' contributions

MJE performed all computational analysis and collected the phenotypic data. AM conceived and participated in the design of the study. Both authors read and approved the final manuscript.

\section{Acknowledgements}

We would like to thank James R. Johnson for his help and technical expertise; we also thank Bob Burgoyne and Jeff Barclay for their helpful suggestions. Some phenotypic data was collected with the help of Timothy Frost. MJE was funded by a Wellcome Trust 4-year PhD studentship.

Received: 4 February 2014 Accepted: 26 August 2014

Published: 2 October 2014 


\section{References}

1. Mitchell DA, Vasudevan A, Linder ME, Deschenes RJ: Protein palmitoylation by a family of DHHC protein S-acyltransferases. J Lipid Res 2006, 47:1118-1127.

2. Camp LA, Verkruyse LA, Afendis SJ, Slaughter CA, Hofmann SL: Molecula cloning and expression of palmitoyl-protein thioesterase. J Biol Chem 1994, 269:23212-23219.

3. Soyombo AA, Hofmann SL: Molecular cloning and expression of palmitoyl-protein thioesterase 2 (PPT2), a homolog of lysosomal palmitoyl-protein thioesterase with a distinct substrate specificity. J Biol Chem 1997, 272:27456-27463.

4. Fukata Y, Fukata M: Protein palmitoylation in neuronal development and synaptic plasticity. Nat Rev Neurosci 2010, 11:161-175.

5. Greaves J, Chamberlain LH: DHHC palmitoyl transferases: substrate interactions and (patho)physiology. Trends Biochem Sci 2011, 36:245-253.

6. Korycka J, Lach A, Heger E, Boguslawska DM, Wolny M, Toporkiewicz M, Augoff K, Korzeniewski J, Sikorski AF: Human DHHC proteins: a spotlight on the hidden player of palmitoylation. Eur J Cell Biol 2012, 91:107-117.

7. Omary MB, Trowbridge IS: Covalent binding of fatty acid to the transferrin receptor in cultured human cells. J Biol Chem 1981, 256:4715-4718.

8. Bohm S, Frishman D, Mewes HW: Variations of the $\mathrm{C} 2 \mathrm{H} 2$ zinc finger motif in the yeast genome and classification of yeast zinc finger proteins. Nucleic Acids Res 1997, 25:2464-2469.

9. Fukata $M$, Fukata $Y$, Adesnik H, Nicoll RA, Bredt DS: Identification of PSD-95 palmitoylating enzymes. Neuron 2004, 44:987-996.

10. Roth AF, Feng Y, Chen L, Davis NG: The yeast DHHC cysteine-rich domain protein Akr1p is a palmitoyl transferase. J Cell Biol 2002, 159:23-28.

11. Bannan BA, Van Etten J, Kohler JA, Tsoi Y, Hansen NM, Sigmon S, Fowler E, Buff H, Williams TS, Ault JG, Glaser RL, Korey CA: The Drosophila protein palmitoylome: characterizing palmitoyl-thioesterases and $\mathrm{DHHC}$ palmitoyl-transferases. Fly (Austin) 2008, 2:198-214.

12. Mitchell DA, Mitchell G, Ling Y, Budde C, Deschenes RJ: Mutational analysis of Saccharomyces cerevisiae Erf2 reveals a two-step reaction mechanism for protein palmitoylation by DHHC enzymes. J Biol Chem 2010, 285:38104-38114.

13. Ohno Y, Kashio A, Ogata R, Ishitomi A, Yamazaki Y, Kihara A: Analysis of substrate specificity of human $\mathrm{DHHC}$ protein acyltransferases using a yeast expression system. Mol Biol Cell 2012, 23:4543-4551.

14. Duncan JA, Gilman AG: A cytoplasmic acyl-protein thioesterase that removes palmitate from $G$ protein alpha subunits and p21(RAS). J Biol Chem 1998, 273:15830-15837.

15. Camp LA, Hofmann SL: Purification and properties of a palmitoyl-protein thioesterase that cleaves palmitate from H-Ras. J Biol Chem 1993, 268:22566-22574

16. Verkruyse LA, Hofmann SL: Lysosomal targeting of palmitoyl-protein thioesterase. J Biol Chem 1996, 271:15831-15836.

17. Lehtovirta M, Kyttala A, Eskelinen EL, Hess M, Heinonen O, Jalanko A Palmitoyl protein thioesterase (PPT) localizes into synaptosomes and synaptic vesicles in neurons: implications for infantile neuronal ceroid lipofuscinosis (INCL). Hum Mol Genet 2001, 10:69-75.

18. Calero G, Gupta P, Nonato MC, Tandel S, Biehl ER, Hofmann SL, Clardy J: The crystal structure of palmitoyl protein thioesterase-2 (PPT2) reveals the basis for divergent substrate specificities of the two lysosomal thioesterases, PPT1 and PPT2. J Biol Chem 2003, 278:37957-37964.

19. Kang R, Wan J, Arstikaitis P, Takahashi H, Huang K, Bailey AO, Thompson JX, Roth AF, Drisdel RC, Mastro R, Green WN, Yates JR 3rd, Davis NG, El-Husseini A: Neural palmitoyl-proteomics reveals dynamic synaptic palmitoylation. Nature 2008, 456:904-909.

20. Roth AF, Wan J, Bailey AO, Sun B, Kuchar JA, Green WN, Phinney BS, Yates JR 3rd, Davis NG: Global analysis of protein palmitoylation in yeast. Cell 2006, 125:1003-1013.

21. Yang W, Di Vizio D, Kirchner M, Steen H, Freeman MR: Proteome scale characterization of human S-acylated proteins in lipid raft-enriched and non-raft membranes. Mol Cell Proteomics 2010, 9:54-70.

22. Dowal L, Yang W, Freeman MR, Steen H, Flaumenhaft R: Proteomic analysis of palmitoylated platelet proteins. Blood 2011, 118:e62-73.

23. Marin EP, Derakhshan B, Lam TT, Davalos A, Sessa WC: Endothelial cell palmitoylproteomic identifies novel lipid-modified targets and potential substrates for protein acyl transferases. Circ Res 2012 110:1336-1344.

24. Merrick BA, Dhungana S, Williams JG, Aloor JJ, Peddada S, Tomer KB, Fessler $\mathrm{MB}$ : Proteomic profiling of S-acylated macrophage proteins identifies a role for palmitoylation in mitochondrial targeting of phospholipid scramblase 3. Mol Cell Proteomics 2011, 10:M110 006007.

25. Kamath RS, Martinez-Campos M, Zipperlen P, Fraser AG, Ahringer J: Effectiveness of specific RNA-mediated interference through ingested double-stranded RNA in Caenorhabditis elegans. Genome Biol 2001, 2: RESEARCH0002. http://www.ncbi.nlm.nih.gov/pubmed.

26. Timmons L, Fire A: Specific interference by ingested dsRNA. Nature 1998 395:854

27. Gleason E, Lindsey WC, Kroft TL, Singson AW, L'Hernault SW: spe-10 encodes a DHHC-CRD zinc-finger membrane protein required for endoplasmic reticulum/Golgi membrane morphogenesis during Caenorhabditis elegans spermatogenesis. Genetics 2006, 172:145-158.

28. Shakes DC, Ward S: Mutations that disrupt the morphogenesis and localization of a sperm-specific organelle in Caenorhabditis elegans. Dev Biol 1989, 134:307-316.

29. Cypser JR, Johnson TE: The spe-10 mutant has longer life and increased stress resistance. Neurobiol Aging 1999, 20:503-512.

30. Porter MY, Turmaine M, Mole SE: Identification and characterization of Caenorhabditis elegans palmitoyl protein thioesterase1. J Neurosci Res 2005, 79:836-848.

31. Vesa J, Hellsten E, Verkruyse LA, Camp LA, Rapola J, Santavuori P, Hofmann SL, Peltonen $L$ : Mutations in the palmitoyl protein thioesterase gene causing infantile neuronal ceroid lipofuscinosis. Nature 1995, 376:584-587.

32. Brenner S: The genetics of Caenorhabditis elegans. Genetics 1974, 77:71-94.

33. Chalfie M, Sulston J: Developmental genetics of the mechanosensory neurons of Caenorhabditis elegans. Dev Biol 1981, 82:358-370.

34. Prescott GR, Gorleku OA, Greaves J, Chamberlain LH: Palmitoylation of the synaptic vesicle fusion machinery. J Neurochem 2009, 110:1135-1149.

35. Kihara A, Kurotsu F, Sano T, Iwaki S, Igarashi Y: Long-chain base kinase Lcb4 Is anchored to the membrane through its palmitoylation by Akr1. Mol Cell Biol 2005, 25:9189-9197.

36. Gonzalez Montoro A, Quiroga R, Maccioni HJ, Valdez Taubas J: A nove motif at the C-terminus of palmitoyltransferases is essential for Swf1 and Pfa3 function in vivo. Biochem J 2009, 419:301-308.

37. Huang $K$, Sanders $S$, Singaraja R, Orban P, Cijsouw T, Arstikaitis P, Yanai A, Hayden MR, El-Husseini A: Neuronal palmitoyl acyl transferases exhibit distinct substrate specificity. FASEB J 2009, 23:2605-2615.

38. Huh WK, Falvo JV, Gerke LC, Carroll AS, Howson RW, Weissman JS, O'Shea EK: Global analysis of protein localization in budding yeast. Nature 2003, 425:686-691.

39. Rual JF, Ceron J, Koreth J, Hao T, Nicot AS, Hirozane-Kishikawa T, Vandenhaute J, Orkin SH, Hill DE, van den Heuvel S, Vidal M: Toward improving Caenorhabditis elegans phenome mapping with an ORFeome-based RNAi library. Genome Res 2004, 14:2162-2168.

40. Fire A, Xu S, Montgomery MK, Kostas SA, Driver SE, Mello CC: Potent and specific genetic interference by double-stranded RNA in Caenorhabditis elegans. Nature 1998, 391:806-811.

41. Simmer F, Tijsterman M, Parrish S, Koushika SP, Nonet ML, Fire A, Ahringer J, Plasterk RH: Loss of the putative RNA-directed RNA polymerase RRF-3 makes C. elegans hypersensitive to RNAi. Curr Biol 2002, 12:1317-1319.

42. Brown AE, Yemini El, Grundy LJ, Jucikas T, Schafer WR: A dictionary of behavioral motifs reveals clusters of genes affecting Caenorhabditis elegans locomotion. Proc Natl Acad Sci U S A 2013, 110:791-796.

43. Yemini E, Jucikas T, Grundy $\sqcup$, Brown AE, Schafer WR: A database of Caenorhabditis elegans behavioral phenotypes. Nat Methods 2013, 10:877-879.

44. Johnson JR, Ferdek P, Lian LY, Barclay JW, Burgoyne RD, Morgan A: Binding of UNC-18 to the N-terminus of syntaxin is essential for neurotransmission in Caenorhabditis elegans. Biochem J 2009, 418:73-80.

45. Miller KG, Emerson MD, Rand JB: Goalpha and diacylglycerol kinase negatively regulate the Gqalpha pathway in C. elegans. Neuron 1999, 24:323-333.

46. Rush DB, Leon RT, McCollum MH, Treu RW, Wei J: Palmitoylation and trafficking of GAD65 are impaired in a cellular model of Huntington's disease. Biochem J 2012, 442:39-48.

47. Velinov M, Dolzhanskaya N, Gonzalez M, Powell E, Konidari I, Hulme W, Staropoli JF, Xin W, Wen GY, Barone R, Coppel SH, Sims K, Brown WT, Zuchner S: Mutations in the gene DNAJC5 cause autosomal dominant Kufs disease in a proportion of cases: study of the Parry family and 8 other families. PLoS One 2012, 7:e29729.

48. Vetrivel KS, Meckler $X$, Chen $Y$, Nguyen PD, Seidah NG, Vassar R, Wong PC, Fukata M, Kounnas MZ, Thinakaran G: Alzheimer disease Abeta production 
in the absence of S-palmitoylation-dependent targeting of BACE1 to lipid rafts. J Biol Chem 2009, 284:3793-3803.

49. Das AK, Lu JY, Hofmann SL: Biochemical analysis of mutations in palmitoyl-protein thioesterase causing infantile and late-onset forms of neuronal ceroid lipofuscinosis. Hum Mol Genet 2001, 10:1431-1439.

50. Singaraja RR, Huang K, Sanders SS, Milnerwood AJ, Hines R, Lerch JP, Franciosi S, Drisdel RC, Vaid K, Young FB, Doty C, Wan J, Bissada N, Henkelman RM, Green WN, Davis NG, Raymond LA, Hayden MR: Altered palmitoylation and neuropathological deficits in mice lacking HIP14. Hum Mol Genet 2011, 20:3899-3909.

51. Sutton LM, Sanders SS, Butland SL, Singaraja RR, Franciosi S, Southwell AL, Doty CN, Schmidt ME, Mui KK, Kovalik V, Young FB, Zhang W, Hayden MR: Hip14l-deficient mice develop neuropathological and behavioural features of Huntington disease. Hum Mol Genet 2013, 22:452-465.

52. Gouda K, Matsunaga Y, Iwasaki T, Kawano T: An altered method of feeding RNAi that knocks down multiple genes simultaneously in the nematode Caenorhabditis elegans. Biosci Biotechnol Biochem 2010, 74:2361-2365.

53. Min K, Kang J, Lee J: A modified feeding RNAi method for simultaneous knock-down of more than one gene in Caenorhabditis elegans. Biotechniques 2010, 48:229-232.

54. Lobo S, Greentree WK, Linder ME, Deschenes RJ: Identification of a Ras palmitoyltransferase in Saccharomyces cerevisiae. J Biol Chem 2002, 277:41268-41273.

55. Simmer F, Moorman C, van der Linden AM, Kuijk E, van den Berghe PV, Kamath RS, Fraser AG, Ahringer J, Plasterk RH: Genome-wide RNAi of C. elegans using the hypersensitive rrf-3 strain reveals novel gene functions. PLOS Biol 2003, 1:E12

56. Greaves J, Gorleku OA, Salaun C, Chamberlain LH: Palmitoylation of the SNAP25 protein family: specificity and regulation by DHHC palmitoyl transferases. J Biol Chem 2010, 285:24629-24638.

57. Hou H, John PAT, Meiringer C, Subramanian K, Ungermann C: Analysis of DHHC acyltransferases implies overlapping substrate specificity and a two-step reaction mechanism. Traffic 2009, 10:1061-1073.

58. Stowers RS, Isacoff EY: Drosophila huntingtin-interacting protein 14 is a presynaptic protein required for photoreceptor synaptic transmission and expression of the palmitoylated proteins synaptosome-associated protein 25 and cysteine string protein. J Neurosci 2007, 27:12874-12883.

59. Ohyama T, Verstreken P, Ly CV, Rosenmund T, Rajan A, Tien AC, Haueter C, Schulze KL, Bellen HJ: Huntingtin-interacting protein 14, a palmitoyl transferase required for exocytosis and targeting of CSP to synaptic vesicles. J Cell Biol 2007, 179:1481-1496.

60. Zinsmaier KE, Eberle KK, Buchner E, Walter N, Benzer S: Paralysis and early death in cysteine string protein mutants of Drosophila. Science 1994, 263:977-980.

61. Kashyap SS, Johnson JR, McCue HV, Chen X, Edmonds MJ, Ayala M, Graham ME, Jenn RC, Barclay JW, Burgoyne RD, Morgan A: Caenorhabditis elegans dnj-14, the orthologue of the DNAJC5 gene mutated in adult onset neuronal ceroid lipofuscinosis, provides a new platform for neuroprotective drug screening and identifies a SIR-2.1-independent action of resveratrol. Hum Mol Genet 2014, in press.

62. Bellizzi JJ 3rd, Widom J, Kemp C, Lu JY, Das AK, Hofmann SL, Clardy J: The crystal structure of palmitoyl protein thioesterase 1 and the molecular basis of infantile neuronal ceroid lipofuscinosis. Proc Natl Acad Sci U S A 2000, 97:4573-4578

63. Devedjiev Y, Dauter Z, Kuznetsov SR, Jones TL, Derewenda ZS: Crystal structure of the human acyl protein thioesterase I from a single X-ray data set to 1.5 A. Structure 2000, 8:1137-1146.

64. Manning G, Whyte DB, Martinez R, Hunter T, Sudarsanam S: The protein kinase complement of the human genome. Science 2002, 298:1912-1934.

65. Sacco F, Perfetto L, Castagnoli L, Cesareni G: The human phosphatase interactome: An intricate family portrait. FEBS Lett 2012, 586:2732-2739.

66. Li W, Bengtson MH, Ulbrich A, Matsuda A, Reddy VA, Orth A, Chanda SK, Batalov S, Joazeiro CA: Genome-wide and functional annotation of human E3 ubiquitin ligases identifies MULAN, a mitochondrial E3 that regulates the organelle's dynamics and signaling. PLOS One 2008, 3:e1487.

67. Claque MJ, Coulson JM, Urbe S: Cellular functions of the DUBs. J Cell Sci 2012, 125:277-286

68. Duncan JA, Gilman AG: Characterization of Saccharomyces cerevisiae acyl-protein thioesterase 1, the enzyme responsible for $\mathrm{G}$ protein alpha subunit deacylation in vivo. J Biol Chem 2002, 277:31740-31752.
69. Dekker FJ, Rocks O, Vartak N, Menninger S, Hedberg C, Balamurugan R, Wetzel S, Renner S, Gerauer M, Scholermann B, Rusch M, Kramer JW, Rauh D, Coates GW, Brunsveld L, Bastiaens PI, Waldmann H: Small-molecule inhibition of APT1 affects Ras localization and signaling. Nat Chem Biol 2010, 6:449-456.

70. Tian L, McClafferty H, Knaus HG, Ruth P, Shipston MJ: Distinct acyl protein transferases and thioesterases control surface expression of calciumactivated potassium channels. J Biol Chem 2012, 287:14718-14725.

71. Letunic I, Bork P: Interactive Tree Of Life (iTOL): an online tool for phylogenetic tree display and annotation. Bioinformatics 2007, 23:127-128.

72. Timmons L, Court DL, Fire A: Ingestion of bacterially expressed dsRNAs can produce specific and potent genetic interference in Caenorhabditis elegans. Gene 2001, 263:103-112.

73. Yang JS, Nam HJ, Seo M, Han SK, Choi Y, Nam HG, Lee SJ, Kim S: OASIS: online application for the survival analysis of lifespan assays performed in aging research. PLoS One 2011, 6:e23525.

doi:10.1186/1471-2164-15-841

Cite this article as: Edmonds and Morgan: A systematic analysis of protein palmitoylation in Caenorhabditis elegans. BMC Genomics 2014 15:841.

\section{Submit your next manuscript to BioMed Central and take full advantage of:}

- Convenient online submission

- Thorough peer review

- No space constraints or color figure charges

- Immediate publication on acceptance

- Inclusion in PubMed, CAS, Scopus and Google Scholar

- Research which is freely available for redistribution

Submit your manuscript at www.biomedcentral.com/submit
C Biomed Central 